\title{
The Gendered Interplay between Success and Well-Being during Transitions \\ Robin Samuel
}

This is an Accepted Manuscript of an article published by Taylor \& Francis Group in

Educational Research on April 14, 2014, available online:

http://dx.doi.org/10.1080/00131881.2014.898915

Background: Young females have been found to out-perform males in terms of grades and university degrees in many studies. At the same time, young women seem to exhibit lower levels of well-being compared with men. Interestingly, little work has evaluated the interplay between educational success and well-being. However, antecedents and consequences of educational success will likely affect life chances and further educational and occupational trajectories.

Purpose: This paper contributes to this important, but as of yet, underdeveloped topic. The interplay between educational success_-conceptualised as successful intergenerational educational mobility—and well-being is analysed as a dynamic, reciprocal, and gendered process.

Sample: Panel data from the Transition from Education to Employment Project (TREE) is used to study the gendered interplay between educational success and well-being. TREE focuses on post-compulsory educational and labour market pathways of the PISA 2000 cohort in Switzerland. It is based on a sample of 6343 young people who left compulsory schooling in 2000. Data were collected annually from 2001 to 2007. At the time of the first interview, the age range of the middle fifty percent of the youths was between 16.5 and 17.3 years.

Design and methods: As previous research shows, episodes of educational mobility will not be evenly distributed over the observed period (e.g., Mare 1980). Thus, an autoregressive cross-lagged mixture model framework is employed to account for the expected unequal dis- 
tribution of the variables over time and the multilevel structure of the data (Samuel, Bergman, and Hupka-Brunner 2013). Within this framework, two modelling approaches are combined to test the implied reciprocal relationship between educational success and well-being. In the Latent Transition Analysis part of the model, success is measured as latent classes with fixed outcome categories. In the Autoregressive Structural Equation part of the model, well-being is specified to correlate over time. Models were estimated separately for males and females so as to allow for different error variances.

Results: The models reveal that mechanisms of social comparison are gendered and operate differently at various stages of the observed period. Young females seem to be more likely to succeed and to experience positive effects in terms of well-being during successful episodes when compared to males. On the downside, females' well-being seems to be more strongly affected by failure.

Conclusions: This paper shows that well-being is a gendered personal resource during the transition to adulthood. These findings contribute to the literature on gender differences in educational success as they show how gender, as a social process, operates to create different success and well-being outcomes.

Keywords: gender; education; success; well-being; intergenerational educational mobility; transition 


\section{Introduction}

It is one of the major social changes of our time that women now outperform men in the field of education in many countries (Buchmann, DiPrete, and McDaniel 2008; Hadjar 2011; Logan and Medford 2011). The implications of this shift are profound. Those who are successful in education will likely benefit from a wider range of life choices and may go on to have better jobs, health, and well-being. As with educational achievement, well-being appears to have a gendered dimension. It is a consistent finding that young males report higher levels of wellbeing and related mental health factors, such as self-esteem (Bayard et al. 2014). Instances of lower well-being among young females have been attributed towards a tendency to have more critical stances with respect to their own physical appearance and the quality of their friendships (Feingold and Mazzella 1998; McHale et al. 2001; Salmela-Aro and Tuominen-Soini 2010). However, a few studies provide evidence that young men’s well-being might become increasingly sensitive to life events and social comparison across cohorts. Young men are increasingly likely to compare themselves to the muscular male ideal as portrayed in the mass media (Barlett, Vowels, and Saucier 2008; Ogbeide et al. 2010). Yet, levels of interpersonal orientation- “the tendency to be concerned with the status of one's relationships and the opinions others hold of oneself”- are still lower among young men (Nolen-Hoeksema 2001: 175). Even though well-being has been described as an end in and of itself since Aristotle (2012 [approx. 330 BC]), research has shown that it might act as a personal resource (Jencks 1979; Lyubomirsky, King, and Diener 2005). In fact, several studies link educational achievement to well-being (e.g., Kriesi, Buchmann, and Jaberg 2012; Michalos 2008). In the context of educational success, Hascher and Hagenauer (2011) emphasise the centrality of well-being. Still, it is unclear how well-being may foster educational success.

From a gender equality perspective, it is crucial, for three reasons, to study how success and well-being are related over time for females and males. First, in labour markets with 
high levels of occupational sex segregation, as is the case with Switzerland and Germany, there is typically little horizontal occupational mobility (Kriesi, Buchmann, and Sacchi 2010). Thus, educational pathways are especially interesting, as post-compulsory schooling performance and experience shape the course of life to a greater extent than in other countries (Blossfeld and Maurice 2011; Krüger and Levy 2000). Second, well-being is an indication of how well people feel about themselves and their achievements (Diener 1984; Veenhoven 1984). If men and women's well-being is variously affected by success and failure, this may indicate different cultural beliefs about gender roles (Connell and Messerschmidt 2005; Correll 2001, 2004; West and Zimmerman 1987). Third, if well-being is used as a gendered resource to encourage success in education, this will contribute to the explanation of why females more often succeed in education.

This paper will explore the patterns underlying the interplay between educational success and well-being. Educational success may entail different concepts (Kriesi et al. 2012). In this research, I use the example of successful and unsuccessful intergenerational educational mobility. This is a relative notion of success as it relates to a person's educational attainment in respect to parental educational attainment. Two questions will be addressed. First, how are effects of success or failure on well-being gendered? Second, how are effects of well-being on successful outcomes gendered? 


\section{The Interplay between Successful Inter-Generational Educational Mobility, Well-Being, and Gender}

The study of various types of success and well-being as reciprocally linked is a relatively new development in economic, educational, psychological, and sociological literature. For example, Samuel et al. (2013) provide evidence that the interplay between educational and early occupational success and well-being is reciprocal and gendered. However, most of the research focuses on either the effects of educational and occupational success on well-being, or, to a lesser extent, the effects of well-being on success.

Recent examples of the former perspective are Hadjar et al. (2008) who identify effects of educational attainment on life satisfaction. Samuel et al. (2011) show that successful or unsuccessful intergenerational transfer of educational attainment affects the stability of well-being. Kriesi et al. (2012) set out to analyse the relative significance of various types of educational success by testing a comprehensive model, which assesses academic achievement in compulsory schooling and post-compulsory education, the expected transition to the type of post-compulsory education, successful intergenerational transmission of educational status, and educational goal achievement. They find that well-being at the age of 18 is best predicted by lower-secondary status attainment and the transition success to post-compulsory education. Although these studies use different data and concepts of educational success, they all make the case that social comparison seems to be one of the main drivers behind well-being, apart from traits such as extraversion and neuroticism.

This observation has been made in numerous other studies (Festinger 1954; Michalos 1985; Oesch and Lipps 2013; Wolbring, Keuschnigg, and Negele 2013). Basically, well-being is thought of as a function of a person's self-evaluation with respect to a reference point, such as another person's educational achievements. Accordingly, if another person has superior educational credentials than oneself, one's well-being might be negatively affected and vice 
versa. From a gender perspective, Bayard et al. (2014) examine trajectories in upper secondary education and the development of well-being using self-esteem as an indicator, taking a social comparison perspective. They find young women's well-being to be more influenced by educational attainment and men's well-being to be inert to the characteristics of their educational trajectories. Hankin and Abramson (2001) show that females are more likely to be negatively affected by life events in terms of depression, which governs later behaviour negatively (Bergman and Scott 2001). Similarly, De Coster (2005) finds that females are more likely to have their well-being influenced by family stress. But why are young women more sensitive to life events and social comparison effects?

One strand of explanation might be found in socialization theory and theories of social interaction (Bourdieu 1998; Gilligan 1990). Women are socialized to take a more comparative perspective, while men are more likely to "deemphasize their connection to others” (KortButler 2008:123). Males and females differ in how they evaluate the opinions others hold of themselves. The levels of interpersonal orientation are consistently higher among girls (Nolen-Hoeksema 2001). Consequently, failing to attain the parents' educational attainment might negatively affect well-being as females are socialized to be more socially orientated and to base their self-concept on interpersonal relations. Another strand within gender socialization theory emphasizes different coping styles (Compas, Orosan, and Grant 1993). For example, Nolen-Hoeksema (2001) points out that life events might affect females more as they tend towards (emotional) rumination. Young men act more according to expected norms of masculinity (Kort-Butler 2008). This includes controlling emotions as well as emphasizing positive aspects in the face of failure. Because females have been found to be more susceptible to social comparison effects, I expect them to be more affected by failure than males. Furthermore, gender-specific coping styles predict a negative effect on well-being. 
As for the effect of well-being on success, the research is comparably sparse (Diener 2009:268). Lyubomirsky and colleagues (2005) reviewed studies which implied causal relationships between happiness—specifically, the long-term propensity to frequently experience positive emotions - and successful outcomes. They report weighted mean effect sizes in the longitudinal studies ranging from .05 to $.29(\mathrm{n}=62)$. Hascher and Hagenauer describe wellbeing as a central aspect of educational success (2011). A few other studies show that wellbeing fosters successful academic outcomes (Gilman and Huebner 2006; Suldo, Thalji, and Ferron 2011). In line with Heineck and Anger (2010), I propose that the effects of well-being on successful intergenerational educational mobility might be understood analogously to the effects of noncognitive characteristics on labour market outcomes. More likely, well-being is associated with success because it is rewarded as a desirable characteristic (Bowles, Gintis, and Osborne 2001). The display of a positive attitude toward life might be considered as an indication of commitment, correct conduct, and even academic performance.

In addition, much like reading skills, well-being might be conceived of as a part of an individual's set of productive traits (Borghans et al. 2008; Heckman, Stixrud, and Urzua 2006). That is, well-being is associated with higher productivity in educational contexts, which will lead to the potential for better marks and signal suitability for promotion to more selective educational pathways. Both views, supply and demand, are complimentary and in this paper I assume that both are at play. In sum, well-being might be associated with desirable educational outcomes and thus successful intergenerational educational mobility because its display is rewarded, and well-being might act as a resource because a generally more positive attitude toward life will likely support goal attainment. I hypothesise that well-being is positively associated with successful intergenerational educational mobility. There is, however, no theoretical basis on which to expect gender differences in how well-being is used as a personal resource. 


\section{Data}

The reciprocal relationship between successful intergenerational educational mobility, wellbeing, and gender is analysed using the Swiss youth panel TREE. It is a nationally representative PISA 2000 follow-up (Adams and Wu 2002; OECD/PISA 2001; TREE 2011). The sample was drawn from a school leaver cohort in 2000 which participated in PISA at the end of compulsory schooling ( $9^{\text {th }}$ grade). It was surveyed annually from 2001 to 2007. An additional wave was collected in 2010. I use the data obtained between 2001 to 2006. For computational reasons, data from 2007 and 2010 cannot be included. However, this will not affect the analyses as gendered pathways have been shown to converge six years after compulsory schooling in Switzerland (Hupka-Brunner et al. 2011). The final sample used for the analyses comprised 2345 men and 2982 women. As the models for men and women are estimated separately, the uneven distribution of gender does not affect the results.

\section{Measures}

Successful intergenerational educational mobility is measured as the difference between parents' level of International Standard Classification of Education (ISCED) 97 and their offspring's educational or occupational position during each wave. This variable takes on three values: success, stable, and failure. For example, a daughter attending university and her parents having an ISCED 97 level of I (i.e., without compulsory education) will create a positive success differential, which is treated as success. If the parent and offspring's educational or occupational levels are the same, this is treated as stable. If the offspring does not attain the parents' level of education, this is conceived of as a failure. Importantly, this variable is treated as nominal. I do not assume the success categories will exhibit any intrinsic or extrinsic order. 
Well-being is quantified as a positive attitude toward life (Grob et al. 1991, 1996). This five item construct was measured at each wave. Exemplary items are: "My future looks bright”, “I am happy with the way my life plan unfolds”, and "My life seems to be meaningful”. The Tucker Lewis Index of .953 for an autoregressive model over 6 waves with autocorrelation, indicates excellent measurement quality of this construct even over time.

There are a series of variables to be accounted for, because well-being and successand their interplay—depend on several factors (Bourdieu and Passeron 1970; Breen and Jonsson 2000; Desjardins 2008; DiPrete and Eirich 2006; Krais 1983; Michalos 2008; Samuel et al. 2013). The following variables and scales represent social background, individual factors, and institutional context. They were all measured in the PISA 2000 survey and are internationally tested (Adams and Wu 2002).

Economic capital. Economic capital or wealth is a multi-item variable including different aspects of familial wealth, such as the number of cars, bathrooms, computers, and cell phones and whether the adolescents have a room of their own (standard deviation (SD) = $0.81)$

Highest International Socio-Economic Index of Occupational Status (HISEI). HISEI is measured by the International Socioeconomic Index of Occupational Status, derived from information about the parents' main job. It provides information on the socio-economic status of the parents. The highest value of the parents was chosen (HISEI; SD = 16.28).

Cultural possession. This variable is operationalised using a multi-item composite variable. Information on the quantity of books, paintings, etc. was combined with more detailed information on the kind of the cultural goods, e.g., whether the household owns classical literature and books of poems $(\mathrm{SD}=6.31)$. 
Reading skills. This is a PISA measure of reading literacy and combines three aspects of reading: "Retrieving, interpreting and reflecting upon and evaluating information” (Adams and $\mathrm{Wu} 2002$ : 200; SD = 89.00).

Economic capital, HISEI, cultural possessions, and reading skills were centred at the grand mean.

Structure of educational and occupational systems. In Switzerland, the Frenchspeaking and German-speaking regions differ from each other with regard to educational and occupational mobility (OPET 2008). Also, there is evidence that young people in the Frenchspeaking region of Switzerland exhibit lower levels of well-being than those in the Germanspeaking region (Semmer et al. 2005). I thus include a dummy for the French and Italianspeaking regions of Switzerland (i.e., Latin; 53.2 percent).

State and path dependency. A young person's educational situation at a given time will determine, to some extent, later educational and occupational outcomes as well as the pathways in their entirety (DiPrete and Eirich 2006). Similarly, well-being at a given time will predict future well-being. I include autoregressive elements in the models to account for this. Future values are modelled as a function of all past values.

\section{Analytical Plan}

This paper will analyse the effects of successful and unsuccessful intergenerational educational mobility on well-being as well as the effects of well-being on successful and unsuccessful intergenerational educational mobility. As previous research shows, episodes of educational mobility will not be evenly distributed over the observed period (e.g., Mare 1980). I use an autoregressive cross-lagged mixture model framework to account for the expected unequal distribution of the variables over time and the multilevel structure of the data. Within this framework, two modelling approaches are combined to test the implied reciprocal relationship 
between success and well-being. More precisely, the model is a combination of Latent Transition Analysis (Humphreys and Janson 2000; Nylund 2007) and Autoregressive Structural Equation Modelling (Curran and Bollen 2001), conditional on a series of time-invariant control variables. In the Latent Transition Analysis part of the model, successful and unsuccessful intergenerational educational mobility is measured as latent classes with fixed outcome categories. In the Autoregressive Structural Equation part of the model, well-being is specified to correlate over time. Intercepts and slopes of autoregressive parts (well-being) are allowed to vary across classes and time. Slopes for time-invariant control variables are allowed to vary across classes and time. Two models, one for females and one for males were estimated using random starts and starting values (Samuel et al. 2013). This allows for different error variances for males and females (Correll 2001).

\section{Results}

\section{Gendered Effects of Intergenerational Educational Mobility on Well-Being}

Figure 1 displays standardised gender differences $(\Delta b)$ between slopes of the autoregressive parts of well-being for the categories success and failure. A negative $\Delta \mathrm{b}$ indicates that the slope is steeper for females, and a positive $\Delta \mathrm{b}$ steeper for males. The steepness of these slopes indicates the effect of success or failure on every single transition between all waves controlling for a series of other variables (Table 1 and 2 in Appendix). Note that the slopes for wellbeing between every time point will always be positive, as well-being at one time point predicts well-being at the subsequent time point. However, the difference $\Delta \mathrm{b}$ between two slopes can be negative. The general picture does not hint at a systematic gendered pattern (Table 1 and 2 in Appendix). Based on this model, females seem to make better use of successful episodes in terms of well-being. Their slopes for well-being are steeper than the males' 80 per- 
cent of the time. Males exhibit steeper slopes in the context of failure more often, i.e., 60 percent of the time. That is, their well-being is less affected by failure.

[Figure 1 about here]

These findings are in line with other research that shows that young women cope less well with adverse external effects, and thus report lower well-being (Salmela-Aro and Tynkkynen 2010). Again, this may be caused by unsuccessful intergenerational educational mobility. As for males, one could hypothesise that failure may affect well-being negatively as anticipated traditional roles as male 'breadwinner' are at risk (see operationalisation of positive attitude toward life; Connell and Messerschmidt 2005). Critical phases are, typically, labour market entry after completing an apprenticeship. In many cases, this occurs between 3 and 5 years upon completion of compulsory schooling (transitions 2003 to 2004 and 2004 to 2005 in Figure 1).

\section{Gendered Effects of Well-Being on Intergenerational Educational Mobility}

The estimates for well-being on success are all positive (in logit scale; Figure 2). Well-being increases the likelihood to experience success. By and large, females seem to make better use of well-being as a personal resource to foster successful outcomes controlling for various social and personal resources (Table 3 and 4 in Appendix). However, this ability seems to decrease over time. The pattern for males is less clear. Their ability to use well-being as a personal resource to be successful seems to increase three years after completion of compulsory schooling.

[Figure 2 about here] 
These findings are consistent with the idea that well-being can be thought of as a personal resource, as some of the literature finds (Bandura 1989; Salmela-Aro and Tuominen-Soini 2010). It allows a person to master challenging situations in an education context.

\section{Discussion and Conclusion}

In this paper, I set out to analyse one of the major social changes of our time: that women now outperform men in education. The analyses support this idea, in line with previous literature. I would like to emphasise three key findings which extend previous studies both theoretically and empirically in that they relate to gender as a social process.

First, the models show that it is a reasonable assumption to conceive of the interplay between well-being and successful and unsuccessful intergenerational educational mobility as a gendered reciprocal relationship. Well-being and successes affect each other, not only on the level of states but also in the form of trajectories. This goes beyond previous research in that the interplay is explicitly modelled as a reciprocal relationship.

Second, in the context of success, females seem to benefit more in terms of wellbeing. Males seem to be less affected by failure. These findings go some way to corroborate the hypothesis that females are more susceptible to social comparison effects and that gendered coping styles are at play mostly due to socialization processes (Coster 2005; Hankin and Abramson 2001; Kort-Butler 2008). Research focusing on how status group membership is associated with well-being might, additionally, help to understand these findings (Branscombe 1998; O’Brien and Major 2005). If females are considered to have, on average, lower societal status than males, they are more likely to be adversely affected by unsuccessful episodes but also to experience a greater positive effect on their well-being when successful. Conversely, males as members of a higher status group in the gender dimension, will likely 
display a more inert well-being pattern (Bayard et al. 2014). Their evaluation of life will, on average, not be as susceptible to events and social comparison. Importantly, the relative inertia of male well-being patterns might also conceal more complex masculinities. For example, low-status men might report constant levels of well-being as a form of compensatory masculinity (Pyke 1996).

The third key finding considers well-being as a personal resource. Young women seem to make better use of this asset to foster successful intergenerational educational mobility. This extends the literature on well-being as a resource by bringing in a gender perspective. Different societal expectations for men and women might explain this finding (West and Zimmerman 1987). In Switzerland, the norm for males is still to be successful and to become a 'breadwinner'. This is regardless of radical economic shifts and dynamics such as the decline of the male breadwinner model due to increased female labour market participation (Crompton 1999). Controlling for common determinants of educational success, this will likely leave less headroom for any other resources to affect educational outcomes. Conversely, it can be argued that women are less expected to succeed by society norms and might, therefore, need every available resource. It is then possible to hypothesize that well-being is a precondition for females to attain success. The decreasing utility of well-being as personal resource for females could be an age effect (Fonseca and Matos 2011). As the data being used are drawn from a school leaver cohort, there is not much variation in age and this assumption will have to be tested in another study.

Further research should address more precisely the mechanisms moderating the gendered interplay between intergenerational educational mobility and well-being. Specifically, the variation across intersections of social class will be sizeable (Browne and Misra 2003; Pyke 1996). Furthermore, self-esteem could moderate the effects of social comparison on well-being. Moreover, it would be crucial to apply other concepts of well-being and success 
likewise to test whether the findings in this study hold for affective well-being and subjective success (Keller, Semmer, Samuel, and Bergman 2014). This could take the form of goal attainment against the backdrop of gendered self-assessments (Correll 2001, 2004). From a social comparison perspective, it would be interesting to examine how the increasing proportion of academically successful young women affects the personal perception of their achievements. This development might fuel new gendered expectations. Likewise, the meaning of failure could change with the declining hegemony of the male breadwinner model. Especially with regard to gender differences, the relationship between success and well-being is likely to continue to be dynamic beyond the examined period. The nature and implications of this interplay could shed light on the challenges females face transforming their credentials and capacities to match occupational positions. This is particularly true in the case of motherhood (Avellar and Smock 2003; Correll, Benard, and Paik 2007).

\section{Acknowledgements}

I am grateful to Manfred Max Bergman, Shelley J. Correll, Andreas Hadjar, Anna Heilbronner Samuel, Sandra Hupka-Brunner, Shireen Kanji, Chris Mitchell, Olga Samuel, the editors of Educational Research, and the participants of the International Conference: "Gender Variations in Educational Success” in Luxembourg October 3 to 5, 2011 for comments on earlier versions of this paper.

\section{Funding}

This research was supported by the Swiss National Science Foundation (grant PBBSP1_141399). 


\section{References}

Adams, Ray, and Magaret Wu, eds. 2002. PISA 2000 Technical Report. Paris: OECD/PISA. Aristotle. 2012. Nicomachean Ethics. Chicago: University of Chicago Press.

Avellar, Sarah, and Pamela J. Smock. 2003. "Has the Price of Motherhood Declined Over Time? A Cross-Cohort Comparison of the Motherhood Wage Penalty.” Journal of Marriage and Family 65(3):597-607.

Bandura, A. 1989. "Regulation of Cognitive Processes through Perceived Self-Efficacy.” Developmental Psychology 25(5):729-35.

Barlett, Christopher P., Christopher L. Vowels, and Donald A. Saucier. 2008. "Meta-Analyses of the Effects of Media Images on Men’s Body-image Concerns.” Journal of Social and Clinical Psychology 27(3):279-310.

Bayard, Sybille, Monika Staffelbach, Philipp Fischer, and Marlis Buchmann. 2014. “UpperSecondary Educational Trajectories and Young Men’s and Women’s Self-Esteem Development in Switzerland.” In Psychological, Educational and Sociological Perspectives on Success and Well-Being in Career Development, edited by Keller, Anita C., Robin Samuel, Manfred Max Bergman, and Norbert K. Semmer. New York: Springer. Bergman, Manfred Max, and Jacqueline Scott. 2001. "Young Adolescents' Wellbeing and Health-Risk Behaviours: Gender and Socio-Economic Differences.” Journal of Adolescence 24:183-97.

Blossfeld, Hans-Peter, and Jutta von Maurice. 2011. “Education as a Lifelong Process.” Zeitschrift für Erziehungswissenschaft 14(2):19-34.

Borghans, Lex, Angela Lee Duckworth, James J. Heckman, and Bas ter Weel. 2008. "The Economics and Psychology of Personality Traits.” Journal of Human Resources 43(4):972-1059.

Bourdieu, Pierre. 1998. La domination masculine. Paris: Ed. du Seuil.

Bourdieu, Pierre, and Jean-Claude Passeron. 1970. La reproduction. Élements pour une théorie du système d'enseignement. Paris: Ed. de Minuit.

Bowles, Samuel, Herbert Gintis, and Melissa Osborne. 2001. "The Determinants of Earnings: A Behavioral Approach.” Journal of Economic Literature 39(4):1137-76.

Branscombe, N. R. 1998. “Thinking About One’s Gender Group’s Privileges or Disadvantages: Consequences for Well-being in Women and Men.” British Journal of Social Psychology 37:167-84.

Breen, Richard, and Jan O. Jonsson. 2000. “Analyzing Educational Careers: A Multinomial Transition Model.” American Sociological Review 65(5):754-72.

Browne, Irene, and Joya Misra. 2003. "The Intersection of Gender and Race in the Labor Market.” Annual Review of Sociology 29:487-513.

Buchmann, Claudia, Thomas A. DiPrete, and Anne McDaniel. 2008. "Gender Inequalities in Education.” Annual Review of Sociology 34:319-37.

Compas, B. E., P. G. Orosan, and K. E. Grant. 1993. “Adolescent Stress and Coping: Implications for Psychopathology During Adolescence.” Journal of Adolescence 16(3):33149.

Connell, R. W., and James W. Messerschmidt. 2005. "Hegemonic Masculinity Rethinking the Concept.” Gender \& Society 19(6):829-59. 
Correll, Shelley J. 2001. "Gender and the Career Choice Process: The Role of Biased Self-Assessments.” American Journal of Sociology 106(6):1691-1730.

Correll, Shelley J. 2004. "Constraints into Preferences: Gender, Status, and Emerging Career Aspirations.” American Sociological Review 69(1):93-113.

Correll, Shelley J., Stephen Benard, and In Paik. 2007. "Getting a Job: Is There a Motherhood Penalty?” American Journal of Sociology 112(5):1297-1339.

Coster, Stacy De. 2005. "Depression and Law Violation: Gendered Responses to Gendered Stresses.” Sociological Perspectives 48(2):155-87.

Crompton, Rosemary. 1999. Restructuring Gender Relations and Employment: The Decline of the Male Breadwinner. Oxford: Oxford University Press.

Curran, Patrick J., and Kenneth A. Bollen. 2001. "The Best of Both Worlds: Combining Autoregressive and Latent Curve Models.” Pp. 105-36 in New Methods for the Analysis of Change, edited by L. M Collins and A. G. (Eds. ) Sayer. Washington, DC: American Psychological Association.

Desjardins, Richard. 2008. "Researching the Links Between Education and Well-being.” European Journal of Education 43(1):23-35.

Diener, Ed. 1984. “Subjective Well-Being.” Psychological Bulletin 95(3):542-75.

Diener, Ed. 2009. The Science of Well-Being: The Collected Works of Ed Diener. New York: Springer.

DiPrete, TA, and GM Eirich. 2006. "Cumulative Advantage as a Mechanism for Inequality: A Review of Theoretical and Empirical Developments.” Annual Review of Sociology 32:271-97.

Feingold, Alan, and Ronald Mazzella. 1998. “Gender Differences in Body Image Are Increasing.” Psychological Science 9(3):190-95.

Festinger, Leon. 1954. “A Theory of Social Comparison Processes.” Human Relations 7(2):117 -140.

Fonseca, Helena, and Margarida G. Matos. 2011. “Are Adolescent Weight-related Problems and General Well-being Essentially an Issue of Age, Gender or Rather a Pubertal Timing Issue?” Journal of Pediatric Endocrinology and Metabolism 24(5-6): 251-256.

Gilligan, Carol. 1990. In a Different Voice: Psychological Theory and Women’s Development. Reissue edition. Harvard: Harvard University Press.

Gilman, Rich, and Scott E. Huebner. 2006. "Characteristics of Adolescents Who Report Very High Life Satisfaction.” Journal of Youth and Adolescence 35(3):293-301.

Grob, Alexander et al. 1991. "Berner Fragebogen Zum Wohlbefinden Jugendlicher (BFW).” Diagnostica 37(1):66-75.

Grob, Alexander, Todd D. Little, Brigitte Wanner, and Alexander J. Wearing. 1996. “Adolescents’ Well-Being and Perceived Control Across 14 Sociocultural Contexts.” Journal of Personality and Social Psychology 71(4):785-95.

Hadjar, Andreas, ed. 2011. Geschlechtsspezifische Bildungsungleichheiten. Wiesbaden: VS Verlag für Sozialwissenschaften.

Hadjar, Andreas, Sigrid Haunberger, and Frank Schubert. 2008. "Bildung Und Subjektives Wohlbefinden Im Zeitverlauf, 1984-2002. Eine Mehrebenenanalyse.” Berliner Journal für Soziologie 18(3):1-31. 
Hankin, B. L., and L. Y. Abramson. 2001. "Development of Gender Differences in Depression: An Elaborated Cognitive Vulnerability-transactional Stress Theory.” Psychological Bulletin 127(6):773-96.

Hascher, Tina, and Gerda Hagenauer. 2011. "Wohlbefinden und Emotionen in der Schule als zentrale Elemente des Schulerfolgs unter der Perspektive geschlechtsspezifischer Ungleichheiten.” Pp. 285-308 in Geschlechtsspezifische Bildungsungleichheiten, edited by Andreas Hadjar. VS Verlag für Sozialwissenschaften.

Heckman, James J., Jora Stixrud, and Sergio Urzua. 2006. "The Effects of Cognitive and Noncognitive Abilities on Labor Market Outcomes and Social Behavior.” Journal of Labor Economics 24(3):411-82.

Heineck, Guido, and Silke Anger. 2010. “The Returns to Cognitive Abilities and Personality Traits in Germany.” Labour Economics 17(3):535-46.

Humphreys, Keith, and Harald Janson. 2000. "Latent Transition Analysis with Covariates, Nonresponse, Summary Statistics and Diagnostics: Modelling Children's Drawing Development.” Multivariate Behavioral Research 35(1):89-118.

Hupka-Brunner, Sandra, Robin Samuel, Evéline Huber, and Manfred Max Bergman. 2011. “Geschlechterungleichheiten im intergenerationalen Bildungstransfer in der Schweiz." Pp. 77-98 in Geschlechtsspezifische Bildungsungleichheiten, edited by Andreas Hadjar. Wiesbaden: VS Verlag für Sozialwissenschaften.

Jencks, Christopher. 1979. Who Gets Ahead?: The Determinants of Economic Success in America. New York: Basic Books.

Keller, Anita C., Norbert K. Semmer, Robin Samuel, and Manfred Max Bergman. 2014. "The Meaning and Measurement of Well-Being as an Indicator of Success.” In Psychological, Educational and Sociological Perspectives on Success and Well-Being in Career Development, edited by Keller, Anita C., Robin Samuel, Manfred Max Bergman, and Norbert K. Semmer. New York: Springer.

Kort-Butler, Lisa A. 2008. "Coping Styles and Sex Differences in Depressive Symptoms and Delinquent Behavior.” Journal of Youth and Adolescence 38(1):122-36.

Krais, Beate. 1983. "Bildung als Kapital. Neue Perspektiven für die Analyse der Sozialstruktur?” Pp. 201-20 in Soziale Ungleichheiten, edited by Reinhard Kreckel. Göttingen: Verlag Otto Schwartz.

Kriesi, Irene, Marlis Buchmann, and Andrea Jaberg. 2012. "Educational Success and Adolescents’ Well-Being in Switzerland.” Schweizerische Zeitschrift für Soziologie 38(2):245-65.

Kriesi, Irene, Marlis Buchmann, and Stefan Sacchi. 2010. "Variation in Job Opportunities for Men and Women in the Swiss Labor Market 1962-1989.” Research in Social Stratification and Mobility 28(3):309-23.

Krüger, H., and R. Levy. 2000. "Masterstatus, Familie und Geschlecht. Vergessene Verknüpfungslogiken zwischen Institutionen des Lebenslaufs.” Berliner Journal für Soziologie 10(3):379-401.

Logan, Sarah, and Emma Medford. 2011. "Gender Differences in the Strength of Association Between Motivation, Competency Beliefs and Reading Skill.” Educational Research 53(1):85-94. 
Lyubomirsky, Sonja, Laura King, and Ed Diener. 2005. "The Benefits of Frequent Positive Affect: Does Happiness Lead to Success?” Psychological Bulletin 131(6):803-55.

Mare, Robert D. 1980. “Social Background and School Continuation Decisions.” Journal of the American Statistical Association 75(370):295-305.

McHale, Susan M., Devon A. Corneal, Ann C. Crouter, and Leann L. Birch. 2001. “Gender and Weight Concerns in Early and Middle Adolescence: Links With Well-Being and Family Characteristics.” Journal of Clinical Child \& Adolescent Psychology 30(3):338-48.

Michalos, Alex C. 1985. "Multiple Discrepancies Theory (MDT).” Social Indicators Research 16(4):347-413.

Michalos, Alex C. 2008. "Education, Happiness and Wellbeing.” Social Indicators Research 87(3):347-66.

Nolen-Hoeksema, Susan. 2001. “Gender Differences in Depression.” Current Directions in Psychological Science 10(5):173-76.

Nylund, Karen Lynn. 2007. “Latent Transition Analysis.” Los Angeles: University of California.

O’Brien, L. T., and B. Major. 2005. "System-justifying Beliefs and Psychological Well-being: The Roles of Group Status and Identity.” Personality and Social Psychology Bulletin 31(12):1718-29.

OECD/PISA (Ed.). (2001). Knowledge and Skills for Life. First Results from PISA 2000. Paris.

Oesch, Daniel, and Oliver Lipps. 2013. "Does Unemployment Hurt Less If There Is More of It Around? A Panel Analysis of Life Satisfaction in Germany and Switzerland.” European Sociological Review 29(5):955-967.

Ogbeide, Stacy A., Christopher A. Neumann, Brian E. Sandoval, and C. Diane Rudebock. 2010. "Gender Differences Between Body Weight and Psychological Well-being During Young Adulthood: A Brief Report.” The New School Psychology Bulletin 8(1).

OPET. 2008. Vocational Education and Training in Switzerland 2008. Facts and Figures. Federal Office for Professional Education and Technology (OPET).

Pyke, Karen D. 1996. “Class-Based Masculinities the Interdependence of Gender, Class, and Interpersonal Power.” Gender \& Society 10(5):527-49.

Salmela-Aro, K., and H. Tuominen-Soini. 2010. “Adolescents’ Life Satisfaction During the Transition to Post-Comprehensive Education: Antecedents and Consequences.” Journal of Happiness Studies 11(6):683-701.

Salmela-Aro, K., and L. Tynkkynen. 2010. "Trajectories of Life Satisfaction Across the Transition to Post-Compulsory Education: Do Adolescents Follow Different Pathways?” Journal of Youth and Adolescence 39(8):870-81.

Samuel, Robin, Manfred Max Bergman, and Sandra Hupka-Brunner. 2013. “The Interplay between Educational Achievement, Occupational Success, and Well-Being.” Social Indicators Research 111(1): 75-96.

Samuel, Robin, Sandra Hupka-Brunner, Barbara E. Stalder, and Manfred Max Bergman. 2011. "Successful and Unsuccessful Intergenerational Transfer of Educational Attainment on Wellbeing in the Swiss Youth Cohort TREE." Swiss Journal of Sociology 37(1): 57-78. 
Semmer, N. K., F. Tschan, A. Elfering, W. Kälin, and S. Grebner. 2005. "Young Adults Entering the Workforce in Switzerland: Working Conditions and Well-Being.” Pp. 16389 in Contemporary Switzerland, edited by H. Kriesi, P. Farago, M. Kohli, and M. Zarin-Nejadan. New York: Palgrave Macmillan.

Suldo, Shannon, Amanda Thalji, and John Ferron. 2011. "Longitudinal Academic Outcomes Predicted by Early Adolescents' Subjective Well-being, Psychopathology, and Mental Health Status Yielded from a Dual Factor Model.” The Journal of Positive Psychology 6(1):17-30.

TREE, ed. 2011. Project Documentation 2000-2010. Basel: TREE.

Veenhoven, Ruut. 1984. Conditions of Happiness. Dordrecht, Boston, Lancaster: D. Reidel Publishing Company.

West, Candace, and Don H. Zimmerman. 1987. “Doing Gender.” Gender \& Society 1(2):125-51.

Wolbring, Tobias, Marc Keuschnigg, and Eva Negele. 2013. “Needs, Comparisons, and Adaptation: The Importance of Relative Income for Life Satisfaction.” European Sociological Review 29(1):86-104. 


\section{Tables and Figures}

Figure 1. Effects of success and failure on well-being slope differences between males and females over time.

0.15

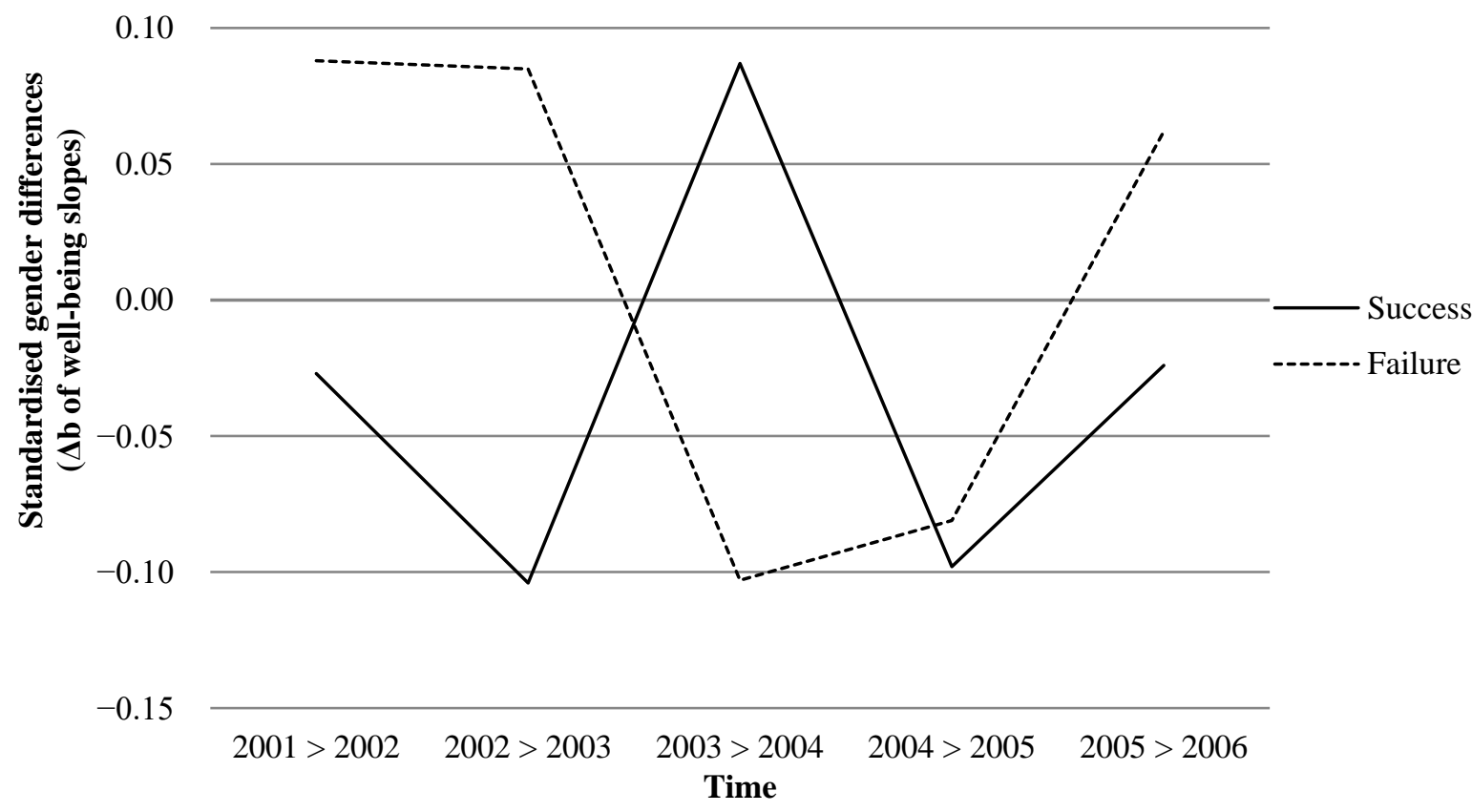

Figure 2. Effects of well-being on success over time (reference category: failure).

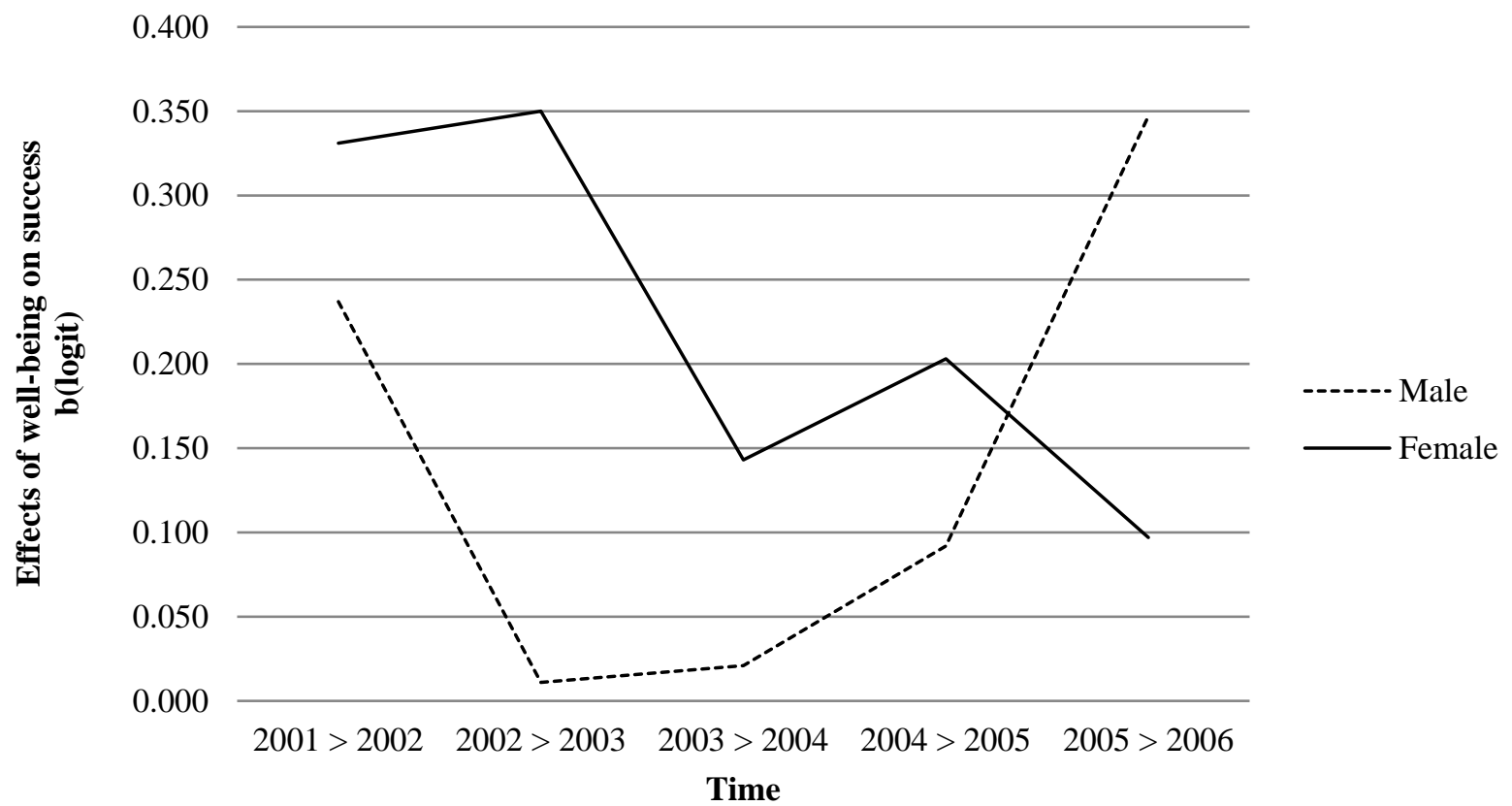




\section{Appendix}

Table 1. Robust maximum likelihood estimates for predictors of well-being, males (n = 2345).

\begin{tabular}{|c|c|c|c|c|c|c|}
\hline & $b$ & S.E.(b) & $b$ & S.E.(b) & $b$ & S.E.(b) \\
\hline $\mathrm{t}_{1 \_ \text {well-being }}$ & \multicolumn{2}{|c|}{ successful } & \multicolumn{2}{|c|}{ stable } & \multicolumn{2}{|c|}{ unsuccessful } \\
\hline Cultural poss. & 0.01 & 0.00 & 0.01 & 0.00 & 0.01 & 0.00 \\
\hline HISEI & $0.00 *$ & 0.00 & $0.00 *$ & 0.00 & $0.00 *$ & 0.00 \\
\hline Economic cap. & $0.07 *$ & 0.03 & $0.07 *$ & 0.03 & $0.07 *$ & 0.03 \\
\hline Reading skills & 0.00 & 0.00 & 0.00 & 0.00 & 0.00 & 0.00 \\
\hline Latin & $-0.25^{* * *}$ & 0.04 & $-0.25 * * *$ & 0.04 & $-0.25 * * *$ & 0.04 \\
\hline Intercept & $0.11^{* * *}$ & 0.03 & $0.11^{* * *}$ & 0.03 & $0.11^{* * *}$ & 0.03 \\
\hline $\mathrm{t}_{2}$ _well-being & \multicolumn{2}{|c|}{ successful } & \multicolumn{2}{|c|}{ stable } & \multicolumn{2}{|c|}{ unsuccessful } \\
\hline Cultural poss. & 0.00 & 0.01 & 0.00 & 0.01 & 0.00 & 0.01 \\
\hline HISEI & 0.00 & 0.00 & 0.00 & 0.00 & 0.00 & 0.00 \\
\hline Economic cap. & -0.07 & 0.05 & -0.02 & 0.04 & 0.00 & 0.05 \\
\hline Reading skills & 0.00 & 0.00 & 0.00 & 0.00 & $0.00 *$ & 0.00 \\
\hline Latin & -0.10 & 0.07 & -0.02 & 0.06 & -0.04 & 0.09 \\
\hline Well-being_ $t_{1}$ & $0.55^{* * *}$ & 0.05 & $0.65 * * *$ & 0.04 & $0.65^{* * *}$ & 0.06 \\
\hline Intercept & 0.03 & 0.05 & -0.02 & 0.04 & 0.00 & 0.05 \\
\hline$t_{3 \_ \text {well-being }}$ & \multicolumn{2}{|c|}{ successful } & \multicolumn{2}{|c|}{ stable } & \multicolumn{2}{|c|}{ unsuccessful } \\
\hline Cultural poss. & 0.00 & 0.01 & 0.00 & 0.01 & -0.01 & 0.01 \\
\hline HISEI & 0.00 & 0.00 & 0.00 & 0.00 & 0.00 & 0.00 \\
\hline Economic cap. & $0.08+$ & 0.04 & -0.04 & 0.04 & $0.11^{*}$ & 0.06 \\
\hline Reading skills & 0.00 & 0.00 & 0.00 & 0.00 & 0.00 & 0.00 \\
\hline Latin & $-0.14^{*}$ & 0.07 & -0.08 & 0.06 & -0.06 & 0.09 \\
\hline Well-being_t $t_{2}$ & $0.57 * * *$ & 0.04 & $0.64 * * *$ & 0.04 & $0.72 * * *$ & 0.05 \\
\hline Intercept & 0.03 & 0.05 & 0.08 & 0.05 & -0.02 & 0.05 \\
\hline t4_well-being & \multicolumn{2}{|c|}{ successful } & \multicolumn{2}{|c|}{ stable } & \multicolumn{2}{|c|}{ unsuccessful } \\
\hline Cultural poss. & 0.00 & 0.01 & 0.00 & 0.01 & 0.00 & 0.01 \\
\hline HISEI & 0.00 & 0.00 & $0.00 *$ & 0.00 & 0.00 & 0.00 \\
\hline Economic cap. & 0.03 & 0.05 & 0.04 & 0.05 & 0.05 & 0.06 \\
\hline Reading skills & 0.00 & 0.00 & $0.00+$ & 0.00 & 0.00 & 0.00 \\
\hline Latin & -0.04 & 0.07 & $-0.11+$ & 0.06 & $-0.24 * *$ & 0.09 \\
\hline Well-being_ $t_{3}$ & $0.72 * * *$ & 0.04 & $0.77 * * *$ & 0.03 & $0.57 * * *$ & 0.05 \\
\hline Intercept & 0.06 & 0.05 & 0.02 & 0.05 & $0.14^{* *}$ & 0.05 \\
\hline $\mathrm{t}_{5 \text { _well-being }}$ & \multicolumn{2}{|c|}{ successful } & \multicolumn{2}{|c|}{ stable } & \multicolumn{2}{|c|}{ unsuccessful } \\
\hline Cultural poss. & -0.01 & 0.01 & 0.00 & 0.01 & 0.01 & 0.01 \\
\hline HISEI & 0.00 & 0.00 & $-0.01^{*}$ & 0.00 & 0.00 & 0.00 \\
\hline Economic cap. & 0.06 & 0.06 & 0.06 & 0.04 & -0.07 & 0.05 \\
\hline Reading skills & 0.00 & 0.00 & 0.00 & 0.00 & 0.00 & 0.00 \\
\hline Latin & 0.01 & 0.08 & 0.06 & 0.07 & $-0.19 *$ & 0.09 \\
\hline Well-being_t4 & $0.57 * * *$ & 0.05 & $0.72 * * *$ & 0.03 & $0.63 * * *$ & 0.05 \\
\hline Intercept & -0.07 & 0.06 & -0.01 & 0.05 & 0.08 & 0.06 \\
\hline t6_well-being & \multicolumn{2}{|c|}{ successful } & \multicolumn{2}{|c|}{ stable } & \multicolumn{2}{|c|}{ unsuccessful } \\
\hline
\end{tabular}




\begin{tabular}{lrccccc}
\hline & $b$ & S.E. $(b)$ & $b$ & S.E. $(b)$ & $b$ & S.E. $(b)$ \\
\hline Cultural poss. & 0.00 & 0.01 & 0.00 & 0.01 & 0.01 & 0.01 \\
HISEI & 0.00 & 0.00 & 0.00 & 0.00 & 0.00 & 0.00 \\
Economic cap. & -0.01 & 0.05 & 0.01 & 0.05 & 0.02 & 0.05 \\
Reading skills & 0.00 & 0.00 & 0.00 & 0.00 & 0.00 & 0.00 \\
Latin & -0.11 & 0.07 & $-0.12+$ & 0.07 & -0.09 & 0.10 \\
Well-being_t $t_{5}$ & $0.65 * * *$ & 0.05 & $0.72^{* * *}$ & 0.04 & $0.70^{* * *}$ & 0.05 \\
Intercept & 0.10 & 0.06 & 0.06 & 0.05 & 0.00 & 0.06 \\
\hline
\end{tabular}

*** $p<0.001 ; * * p<0.01 ; * p<0.05 ;+p<0.1$.

$\mathrm{b}=$ standardised effect of variable; S.E.(b) = standard error of standardised effect of variable.

Key: Cultural poss. = quantity and kind of cultural goods in the household; HISEI = socio-economic status of the parents; Economic cap. = familial wealth; Reading skills = PISA measure of reading literacy; Latin = a variable indicating whether the young person lives in the French and Italian-speaking regions of Switzerland (reference category: German-speaking region); Well-being_ $\mathrm{t}_{\mathrm{n}}=$ well-being measured in previous data collection; Intercept $=$ constant term of the equation.

Table 2. Robust maximum likelihood estimates for predictors of well-being, females $(n=2982)$.

\begin{tabular}{|c|c|c|c|c|c|c|}
\hline & $b$ & S.E.(b) & $b$ & S.E.(b) & $b$ & S.E.(b) \\
\hline $\mathrm{t}_{1 \_ \text {well-being }}$ & \multicolumn{2}{|c|}{ successful } & \multicolumn{2}{|c|}{ stable } & \multicolumn{2}{|c|}{ unsuccessful } \\
\hline Cultural poss. & 0.01 & 0.00 & 0.01 & 0.00 & 0.01 & 0.00 \\
\hline HISEI & 0.00 & 0.00 & 0.00 & 0.00 & 0.00 & 0.00 \\
\hline Economic cap. & 0.03 & 0.03 & 0.03 & 0.03 & 0.03 & 0.03 \\
\hline Reading skills & 0.00 & 0.00 & 0.00 & 0.00 & 0.00 & 0.00 \\
\hline Latin & $-0.39 * * *$ & 0.04 & $-0.39 * * *$ & 0.04 & $-0.39 * * *$ & 0.04 \\
\hline Intercept & $0.19 * * *$ & 0.03 & $0.19 * * *$ & 0.03 & $0.19 * * *$ & 0.03 \\
\hline t2_well-being & \multicolumn{2}{|c|}{ successful } & \multicolumn{2}{|c|}{ stable } & \multicolumn{2}{|c|}{ unsuccessful } \\
\hline Cultural poss. & 0.00 & 0.01 & 0.00 & 0.01 & -0.01 & 0.01 \\
\hline HISEI & 0.00 & 0.00 & 0.00 & 0.00 & 0.00 & 0.00 \\
\hline Economic cap. & 0.03 & 0.03 & 0.04 & 0.04 & -0.01 & 0.05 \\
\hline Reading skills & $0.00+$ & 0.00 & 0.00 & 0.00 & 0.00 & 0.00 \\
\hline Latin & $-0.09+$ & 0.05 & $-0.19 * * *$ & 0.05 & $-0.19^{*}$ & 0.08 \\
\hline Well-being_ $t_{1}$ & $0.58^{* * *}$ & 0.03 & $0.62 * * *$ & 0.03 & $0.56^{* * *}$ & 0.05 \\
\hline Intercept & 0.02 & 0.04 & $0.07+$ & 0.04 & $0.12^{*}$ & 0.05 \\
\hline $\mathrm{t}_{3 \text { _well-being }}$ & \multicolumn{2}{|c|}{ successful } & \multicolumn{2}{|c|}{ stable } & \multicolumn{2}{|c|}{ unsuccessful } \\
\hline Cultural poss. & 0.01 & 0.00 & 0.01 & 0.01 & 0.00 & 0.01 \\
\hline HISEI & $0.00 *$ & 0.00 & 0.00 & 0.00 & 0.00 & 0.00 \\
\hline Economic cap. & 0.04 & 0.03 & -0.02 & 0.04 & -0.06 & 0.06 \\
\hline Reading skills & 0.00 & 0.00 & 0.00 & 0.00 & 0.00 & 0.00 \\
\hline Latin & $-0.08+$ & 0.05 & $-0.13^{*}$ & 0.06 & $-0.18+$ & 0.10 \\
\hline Well-being_ $\mathrm{t}_{2}$ & $0.67 * * *$ & 0.03 & $0.68^{* * *}$ & 0.04 & $0.63^{* * *}$ & 0.06 \\
\hline Intercept & 0.04 & 0.04 & 0.02 & 0.04 & $0.12+$ & 0.06 \\
\hline t4_well-being & \multicolumn{2}{|c|}{ successful } & \multicolumn{2}{|c|}{ stable } & \multicolumn{2}{|c|}{ unsuccessful } \\
\hline Cultural poss. & 0.00 & 0.00 & 0.00 & 0.00 & 0.01 & 0.01 \\
\hline
\end{tabular}




\begin{tabular}{|c|c|c|c|c|c|c|}
\hline & $b$ & S.E.(b) & $b$ & S.E.(b) & $b$ & S.E.(b) \\
\hline HISEI & $0.00+$ & 0.00 & 0.00 & 0.00 & 0.00 & 0.00 \\
\hline Economic cap. & -0.03 & 0.03 & 0.05 & 0.03 & -0.10 & 0.07 \\
\hline Reading skills & $0.00+$ & 0.00 & 0.00 & 0.00 & $0.00 *$ & 0.00 \\
\hline Latin & $-0.17 * * *$ & 0.05 & -0.08 & 0.05 & -0.10 & 0.10 \\
\hline Well-being_t $t_{3}$ & $0.63^{* * *}$ & 0.03 & $0.64^{* * *}$ & 0.03 & $0.68^{* * *}$ & 0.06 \\
\hline Intercept & $0.10 * *$ & 0.04 & 0.05 & 0.04 & 0.04 & 0.07 \\
\hline t5_well-being & \multicolumn{2}{|c|}{ successful } & \multicolumn{2}{|c|}{ stable } & \multicolumn{2}{|c|}{ unsuccessful } \\
\hline Cultural poss. & $-0.01^{*}$ & 0.01 & 0.00 & 0.01 & -0.01 & 0.01 \\
\hline HISEI & 0.00 & 0.00 & 0.00 & 0.00 & 0.00 & 0.00 \\
\hline Economic cap. & 0.06 & 0.04 & -0.02 & 0.04 & -0.01 & 0.06 \\
\hline Reading skills & 0.00 & 0.00 & 0.00 & 0.00 & 0.00 & 0.00 \\
\hline Latin & -0.08 & 0.05 & $-0.12^{*}$ & 0.06 & $-0.22 * *$ & 0.09 \\
\hline Well-being_t $t_{4}$ & $0.67^{* * *}$ & 0.04 & $0.65^{* * *}$ & 0.03 & $0.71^{* * *}$ & 0.05 \\
\hline Intercept & 0.04 & 0.04 & $0.07+$ & 0.04 & 0.01 & 0.06 \\
\hline $\mathrm{t}_{6 \_ \text {well-being }}$ & \multicolumn{2}{|c|}{ successful } & \multicolumn{2}{|c|}{ stable } & \multicolumn{2}{|c|}{ unsuccessful } \\
\hline Cultural poss. & 0.01 & 0.01 & 0.01 & 0.01 & 0.00 & 0.01 \\
\hline HISEI & 0.00 & 0.00 & 0.00 & 0.00 & $-0.01^{*}$ & 0.00 \\
\hline Economic cap. & $0.07+$ & 0.04 & 0.02 & 0.05 & 0.06 & 0.05 \\
\hline Reading skills & 0.00 & 0.00 & 0.00 & 0.00 & 0.00 & 0.00 \\
\hline Latin & -0.09 & 0.06 & $-0.14^{*}$ & 0.06 & $-0.19^{*}$ & 0.08 \\
\hline Well-being_t $t_{5}$ & $0.68^{* * *}$ & 0.03 & $0.69^{* * *}$ & 0.04 & $0.63^{* * *}$ & 0.05 \\
\hline Intercept & $0.07+$ & 0.04 & 0.02 & 0.04 & $0.12^{*}$ & 0.05 \\
\hline
\end{tabular}

$* * * p<0.001 ; * * p<0.01 ; * p<0.05 ;+p<0.1$.

$\mathrm{b}=$ standardised effect of variable; S.E.(b) = standard error of standardised effect of variable.

Key: Cultural poss. = quantity and kind of cultural goods in the household; HISEI = socio-economic status of the parents; Economic cap. = familial wealth; Reading skills = PISA measure of reading literacy; Latin = a variable indicating whether the young person lives in the French and Italian-speaking regions of Switzerland (reference category: German-speaking region); Well-being_ $\mathrm{t}_{\mathrm{n}}=$ well-being measured in previous data collection; Intercept $=$ constant term of the equation.

Table 3. Maximum likelihood robust logit estimates for predictors of success and stable achievement for males (reference category: failure; $n=2345$; autoregressive elements not shown).

\begin{tabular}{lrrrr}
\hline & $b$ & S.E. $(b)$ & $b$ & S.E. (b) \\
\hline & t1_success & & t1_stability & \\
Latin & $0.67^{* * *}$ & 0.12 & $0.58^{* * *}$ & 0.11 \\
Reading skills & $0.01^{* * *}$ & 0.00 & $0.00^{* * *}$ & 0.00 \\
Economic cap. & $-0.40^{* * *}$ & 0.08 & $-0.25^{* * *}$ & 0.07 \\
HISEI & $-0.05^{* * *}$ & 0.00 & $-0.01^{* * *}$ & 0.00 \\
Cultural poss. & -0.01 & 0.01 & 0.01 & 0.01 \\
Constant & -0.01 & 0.08 & $0.38^{* * *}$ & 0.08 \\
\hline
\end{tabular}




\begin{tabular}{|c|c|c|c|c|}
\hline & $b$ & S.E. (b) & $b$ & S.E. (b) \\
\hline \multicolumn{3}{|c|}{ t2_success } & \multicolumn{2}{|l|}{ t2_stability } \\
\hline Latin & -0.37 & 0.32 & $0.50^{*}$ & 0.26 \\
\hline Reading skills & 0.00 & 0.00 & $0.00^{*}$ & 0.00 \\
\hline Economic cap. & $-0.46^{*}$ & 0.19 & $-0.38^{*}$ & 0.17 \\
\hline HISEI & $-0.05^{* * *}$ & 0.01 & $-0.02^{*}$ & 0.01 \\
\hline Cultural poss. & 0.01 & 0.03 & 0.02 & 0.02 \\
\hline Well-being_ $\mathrm{t}_{1}$ & 0.24 & 0.17 & $0.30^{*}$ & 0.12 \\
\hline Constant & $-4.67 * * *$ & 0.53 & $-2.23 * * *$ & 0.18 \\
\hline \multicolumn{3}{|c|}{ t3_success } & \multicolumn{2}{|l|}{ t3_stability } \\
\hline Latin & $-0.98^{*}$ & 0.46 & -0.42 & 0.34 \\
\hline Reading skills & 0.00 & 0.00 & 0.00 & 0.00 \\
\hline Economic cap. & -0.16 & 0.27 & -0.12 & 0.19 \\
\hline HISEI & -0.01 & 0.02 & 0.00 & 0.01 \\
\hline Cultural poss. & 0.02 & 0.04 & 0.02 & 0.03 \\
\hline Well-being_ $\mathrm{t}_{2}$ & 0.01 & 0.31 & -0.19 & 0.24 \\
\hline Constant & $-5.71^{* * *}$ & 1.05 & $-3.19 * * *$ & 0.26 \\
\hline \multicolumn{3}{|c|}{ t4_success } & \multicolumn{2}{|l|}{ t4_stability } \\
\hline Latin & $1.89^{* * *}$ & 0.30 & $1.13^{* * *}$ & 0.21 \\
\hline Reading skills & $-0.01 * * *$ & 0.00 & $0.00^{* *}$ & 0.00 \\
\hline Economic cap. & 0.27 & 0.17 & 0.18 & 0.13 \\
\hline HISEI & $-0.02 *$ & 0.01 & $-0.01^{*}$ & 0.01 \\
\hline Cultural poss. & 0.02 & 0.02 & 0.00 & 0.02 \\
\hline Well-being_ $t_{3}$ & 0.02 & 0.16 & 0.09 & 0.10 \\
\hline Constant & $-14.16^{* * *}$ & 0.31 & $-3.60 * * *$ & 0.30 \\
\hline \multicolumn{3}{|c|}{ t5_success } & \multicolumn{2}{|l|}{ t5_stability } \\
\hline Latin & -0.13 & 0.22 & -0.18 & 0.17 \\
\hline Reading skills & 0.00 & 0.00 & 0.00 & 0.00 \\
\hline Economic cap. & -0.11 & 0.14 & -0.08 & 0.11 \\
\hline HISEI & $-0.02 *$ & 0.01 & 0.00 & 0.01 \\
\hline Cultural poss. & -0.01 & 0.02 & -0.01 & 0.01 \\
\hline Well-being_t $t_{4}$ & 0.09 & 0.11 & 0.10 & 0.09 \\
\hline Constant & $-12.99 * * *$ & 0.18 & $-1.95 * * *$ & 0.16 \\
\hline \multicolumn{3}{|c|}{ t6_success } & \multicolumn{2}{|l|}{ t6_stability } \\
\hline Latin & -0.36 & 0.23 & -0.20 & 0.18 \\
\hline Reading skills & $0.00^{*}$ & 0.00 & 0.00 & 0.00 \\
\hline Economic cap. & 0.24 & 0.15 & 0.05 & 0.11 \\
\hline HISEI & $-0.02 *$ & 0.01 & $0.01+$ & 0.01 \\
\hline Cultural poss. & $-0.03+$ & 0.02 & -0.01 & 0.01 \\
\hline Well-being_ $\mathrm{t}_{5}$ & $0.35^{* *}$ & 0.13 & $0.20^{*}$ & 0.10 \\
\hline Constant & $-5.88 * * *$ & 0.81 & $-1.37 * * *$ & 0.15 \\
\hline
\end{tabular}

*** $p<0.001 ; * * p<0.01 ; * p<0.05 ;+p<0.1$.

$\mathrm{b}=$ standardised effect of variable; S.E.(b) $=$ standard error of standardised effect of variable. 
Key: Cultural poss. $=$ quantity and kind of cultural goods in the household; HISEI $=$ socio-economic status of the parents; Economic cap. = familial wealth; Reading skills = PISA measure of reading literacy; Latin = a variable indicating whether the young person lives in the French and Italian-speaking regions of Switzerland (reference category: German-speaking region); Well-being_ $\mathrm{t}_{\mathrm{n}}=$ well-being measured in previous data collection; Intercept $=$ constant term of the equation.

Table 4. Maximum likelihood robust logit estimates for predictors of success and stable achievement for females (reference category: failure; $n=2982$; autoregressive elements not shown).

\begin{tabular}{|c|c|c|c|c|}
\hline & $b$ & S.E. (b) & $b$ & S.E. (b) \\
\hline \multicolumn{3}{|l|}{ t1_success } & t1_stability & \\
\hline Latin & $0.94^{* * *}$ & 0.11 & $0.44 * * *$ & 0.11 \\
\hline Reading skills & $0.01^{* * *}$ & 0.00 & $0.00^{* * *}$ & 0.00 \\
\hline Economic cap. & $-0.17^{*}$ & 0.07 & $-0.13+$ & 0.07 \\
\hline HISEI & $-0.02^{* * *}$ & 0.00 & 0.00 & 0.00 \\
\hline Cultural poss. & $-0.03^{* *}$ & 0.01 & -0.01 & 0.01 \\
\hline Constant & $0.31^{* * *}$ & 0.08 & $0.65 * * *$ & 0.07 \\
\hline \multicolumn{3}{|l|}{ t2_success } & t2_stability & \\
\hline Latin & 0.18 & 0.23 & $0.65^{* * *}$ & 0.19 \\
\hline Reading skills & 0.00 & 0.00 & $0.01^{* * *}$ & 0.00 \\
\hline Economic cap. & -0.17 & 0.14 & -0.09 & 0.12 \\
\hline HISEI & $-0.04 * * *$ & 0.01 & -0.01 & 0.01 \\
\hline Cultural poss. & -0.03 & 0.02 & -0.02 & 0.02 \\
\hline Well-being_ $\mathrm{t}_{1}$ & $0.33^{* *}$ & 0.12 & $0.20+$ & 0.11 \\
\hline Constant & $-2.79 * * *$ & 0.23 & $-1.22 * * *$ & 0.14 \\
\hline \multicolumn{3}{|l|}{ t3_success } & t3_stability & \\
\hline Latin & $-1.29 * * *$ & 0.32 & -0.25 & 0.26 \\
\hline Reading skills & 0.00 & 0.00 & $0.00 * *$ & 0.00 \\
\hline Economic cap. & $-0.34+$ & 0.20 & -0.21 & 0.16 \\
\hline HISEI & $-0.02 *$ & 0.01 & -0.01 & 0.01 \\
\hline Cultural poss. & -0.03 & 0.02 & -0.02 & 0.02 \\
\hline Well-being_ $t_{2}$ & $0.35 *$ & 0.15 & 0.14 & 0.14 \\
\hline Constant & $-3.13^{* * *}$ & 0.35 & $-1.90 * * *$ & 0.19 \\
\hline \multicolumn{3}{|c|}{ t4_success } & t4_stability & \\
\hline Latin & $1.07^{* * *}$ & 0.20 & $0.45^{* *}$ & 0.15 \\
\hline Reading skills & $0.00^{* *}$ & 0.00 & $0.00^{*}$ & 0.00 \\
\hline Economic cap. & -0.16 & 0.12 & -0.05 & 0.09 \\
\hline HISEI & $-0.01^{*}$ & 0.01 & -0.01 & 0.01 \\
\hline Cultural poss. & 0.00 & 0.02 & 0.00 & 0.01 \\
\hline Well-being_ $t_{3}$ & 0.14 & 0.09 & 0.01 & 0.07 \\
\hline Constant & $-5.22^{* * *}$ & 0.60 & $-2.31^{* * *}$ & 0.20 \\
\hline \multicolumn{3}{|c|}{ t5_success } & t5_stability & \\
\hline Latin & $-0.91^{* * *}$ & 0.19 & $-0.60 * * *$ & 0.15 \\
\hline
\end{tabular}




\begin{tabular}{lcccc}
\hline & $b$ & S.E. $(b)$ & $b$ & S.E. $(b)$ \\
\hline Reading skills & 0.00 & 0.00 & $0.00+$ & 0.00 \\
Economic cap. & -0.05 & 0.13 & -0.14 & 0.10 \\
HISEI & $-0.02^{*}$ & 0.01 & 0.00 & 0.01 \\
Cultural poss. & 0.00 & 0.02 & 0.02 & 0.01 \\
Well-being_t 4 & $0.20^{*}$ & 0.09 & 0.03 & 0.07 \\
Constant & $-4.43^{* * *}$ & 0.54 & $-1.77^{* * *}$ & 0.17 \\
\hline & t6_success & & t6_stability & \\
Latin & $-0.42+$ & 0.22 & $-0.35^{*}$ & 0.18 \\
Reading skills & $0.00^{*}$ & 0.00 & 0.00 & 0.00 \\
Economic cap. & $-0.33^{*}$ & 0.13 & -0.07 & 0.10 \\
HISEI & 0.00 & 0.01 & 0.01 & 0.01 \\
Cultural poss. & -0.02 & 0.02 & 0.01 & 0.01 \\
Well-being_t & 0.10 & 0.11 & 0.01 & 0.09 \\
Constant & $-5.81^{* * *}$ & 0.94 & $-1.76^{* * *}$ & 0.17 \\
\hline
\end{tabular}

*** $p<0.001 ; * * p<0.01 ; * p<0.05 ;+p<0.1$.

$\mathrm{b}=$ standardised effect of variable; S.E.(b) = standard error of standardised effect of variable.

Key: Cultural poss. = quantity and kind of cultural goods in the household; HISEI = socio-economic status of the parents; Economic cap. = familial wealth; Reading skills = PISA measure of reading literacy; Latin = a variable indicating whether the young person lives in the French and Italian-speaking regions of Switzerland (reference category: German-speaking region); Well-being_tn = well-being measured in previous data collection; Intercept $=$ constant term of the equation. 
Table 6. Model fit indices for all models. Log Likelihood (LogL), AIC, BIC, and sample size adjusted BIC (BIC adj.) for the different models. Note that they are not strictly nested due to Full Information Maximum Likelihood estimation.

\begin{tabular}{|c|c|c|c|c|c|c|}
\hline Covariates & $\log L$ & $A I C$ & $B I C$ & BIC adj. & $n$ & $\begin{array}{l}\text { No. of pa- } \\
\text { rameters }\end{array}$ \\
\hline none & -33992.481 & 68218.962 & 68977.450 & 68605.667 & 4831 & 117 \\
\hline Cultural poss. & -45625.854 & 91525.709 & 92437.950 & 92002.604 & 5760 & 137 \\
\hline Cultural poss., HISEI & -41900.174 & 84110.348 & 85130.477 & 84637.937 & 5332 & 155 \\
\hline $\begin{array}{l}\text { Cultural poss., HISEI, } \\
\text { economic cap. }\end{array}$ & -41847.432 & 84040.865 & 85179.428 & 84629.690 & 5331 & 173 \\
\hline $\begin{array}{l}\text { Cultural poss., HISEI, } \\
\text { economic cap., reading } \\
\text { skills }\end{array}$ & -41706.784 & 83795.569 & 85052.453 & 84445.516 & 5327 & 191 \\
\hline $\begin{array}{l}\text { Cultural poss., HISEI, } \\
\text { economic cap., reading } \\
\text { skills, female }\end{array}$ & -41619.015 & 83656.030 & 85031.364 & 84367.229 & 5327 & 209 \\
\hline $\begin{array}{l}\text { Cultural poss., HISEI, } \\
\text { economic cap., reading } \\
\text { skills, female, Latin }\end{array}$ & -41365.891 & 83185.783 & 84679.566 & 83958.233 & 5327 & 227 \\
\hline $\begin{array}{l}\text { All covariates (see } \\
\text { above), covariates al- } \\
\text { lowed to vary across } \\
\text { classes and time: }\end{array}$ & $\log L$ & $A I C$ & $B I C$ & BIC adj. & $n$ & $\begin{array}{l}\text { No. of pa- } \\
\text { rameters }\end{array}$ \\
\hline Latin & -41360.301 & 83194.602 & 84754.191 & 84001.081 & 5327 & 237 \\
\hline Latin, female & -41355.507 & 83205.014 & 84830.408 & 84045.521 & 5327 & 247 \\
\hline $\begin{array}{l}\text { Latin, female, reading } \\
\text { skills }\end{array}$ & -41346.309 & 83206.618 & 84897.818 & 84081.155 & 5327 & 257 \\
\hline $\begin{array}{l}\text { Latin, female, reading } \\
\text { skills, economic cap. }\end{array}$ & -41343.490 & 83218.979 & 84969.404 & 84124.141 & 5327 & 267 \\
\hline $\begin{array}{l}\text { Latin, female, reading } \\
\text { skills, economic cap., } \\
\text { HISEI }\end{array}$ & -41335.290 & 83222.580 & 85038.810 & 84161.770 & 5327 & 277 \\
\hline $\begin{array}{l}\text { Latin, female, reading } \\
\text { skills, economic cap., } \\
\text { HISEI, cultural poss. }\end{array}$ & -41331.274 & 83234.548 & 85116.584 & 84207.768 & 5327 & 287 \\
\hline Females only & -24489.328 & 49496.655 & 51050.746 & 50227.803 & 2982 & 259 \\
\hline Males only & -16638.027 & 33794.054 & 35285.905 & 34463.009 & 2345 & 259 \\
\hline
\end{tabular}

